\title{
ISOLISME: HOBBES REINTERPRETADO POR SADE
}

\section{ISOLISME: HOBBES REINTERPRETED BY SADE}

\author{
Natalia LORENA ZORRILLA* \\ CONICET - Universidad de Buenos Aires
}

Resumen: Este artículo aborda el concepto de «isolisme» en dos obras de Donatien Alphonse François de Sade, La Nouvelle Justine e Histoire de Juliette, estudiando los distintos sentidos que este término adopta y las argumentaciones que los distintos personajes filósofos y filósofas despliegan a propósito de él, favorable o críticamente. Nuestra propuesta consiste en realizar este análisis reparando en el insoslayable diálogo que plantea Sade con la tradición de pensamiento contractualista (nos concentraremos en la línea hobbesiana), mostrando cómo se interpretan, se discuten y se representan conceptual y literariamente nociones claves de esta tradición en los dos textos elegidos.

Palabras Clave: Sade; Hobbes; Isolisme; Estado de naturaleza.

Aвstract: This paper studies the concept of «isolisme» in two works written by Donatien Alphonse François de Sade, La Nouvelle Justine and Histoire de Juliette, by analyzing the different meanings it adopts and the arguments for and against developed by Sade's libertine philosophical characters with regards to it. Our aim is to examine the unavoidable dialogue Sade establishes with the social contract tradition (we will focus on the Hobbesian line), showing how Sadean libertine characters interpret, discuss and represent (literarily and conceptually) the key notions of this tradition of political thought.

Keywords: Sade; Hobbes; Isolisme; State of Nature.

\footnotetext{
* Becaria postdoctoral del CONICET. Instituto de Filosofía Dr. Alejandro Korn, Puan 480, 4to piso.n.zorrilla@conicet.gov.ar// nat.zorrilla@gmail.com.
} 


\section{Introducción}

Desde los albores del siglo XX, la figura de Donatien Alphonse François de Sade (1740-1814) resulta central para pensar el movimiento de la Ilustración. La sombra «Sade», necesaria contrapartida «des Lumières», se extiende sobre gran parte de la filosofía europea del siglo pasado. Adorno y Horkheimer en su Dialéctica de la Ilustración (1944; 1947) establecen la diada Kant-Sade como anverso y reverso de un mismo despliegue continuo de fuerzas correspondiente al movimiento de secularización y desacralización propugnado por el avance de la Ilustración, en el cual la Razón, instrumental y calculadora (vinculada al desarrollo de la burguesía), busca expandirse sistemáticamente para someter y fagocitar todo lo que le es exterior. La historiografía más reciente, de fines del siglo XX, tendió a ver en Sade, por el contrario, un dispositivo de radicalización del pensamiento de los philosophes (Deprun [Sade \& Delon (Ed.), 1990, t. I: LIX-LXIX]; Delon [Sade \& Delon (Ed.), 1900, t. I: IX-LVIII]; Warman [2002]), esto es: Sade como un "fils naturel» ${ }^{1}$ de estos, que, no obstante, lleva al extremo sus presupuestos, exponiendo los puntos débiles de su proyectada moral secular de la virtud. Aún más recientes son los aportes de Céline Spector (2016) en su Éloges de l'injustice y de Gilles Gourbin (2014, 2015, 2016), en los que se evidencia la importancia de Sade como interlocutor crítico del pensamiento político moderno, puntualmente del contractualismo ${ }^{2}$.

\footnotetext{
${ }^{1}$ La frase es de Jean Deprun (Sade \& Delon [Ed.], 1990). Este autor destaca, no obstante, tres aristas del pensamiento de Sade que lo distinguirían de sus predecesores: el isolisme, el intensivisme y el antiphysisme. Michel Delon continúa sobre esta línea: «Quand il fait de ses œuvres de véritables marqueteries d'emprunts, il agit sans doute en plagiaire soucieux d'allonger des livres qui lui sont payés à la page, mais aussi en philosophe qui diffuse les arguments de ses frères de combat et surtout en artiste du collage qui détourne les Lumières en une Philosophie du crime et le libertinage en une danse de mort» (Sade \& Delon [Ed.], 1900: LV). Caroline Warman (2002), por su parte, ve en Sade la culminación de la tradición que ella denomina «sensationist materialism», argumentando que la expresión pornográfica que despliega Sade en sus obras surge de estos mismos presupuestos materialistas compartidos por los autores «sensacionistas», los cuales Sade «dramatiza» y «literaliza» en sus novelas.

2 Céline Spector (2016) estudia ciertas figuras políticas «marginales» que se resisten a reconocer la legitimidad del pacto social, integrando a Sade en este recorrido: el necio en Hobbes, el razonador violento en Diderot, el hombre independiente en Rousseau, el «bribón inteligente/ racional» en Hume y el (maestro) libertino en Sade. Gilles Gourbin $(2014,2015,2016)$ por su parte se concentra en la tríada Diderot-Rousseau-Sade para mostrar cómo este último se hace eco de las críticas de Rousseau a Diderot, usando un autor en contra del otro.
} 
Siguiendo esta misma línea, este artículo se propone explorar la noción de «aislacionismo» (isolisme) en dos obras de Sade, La Nouvelle Justine (1799) ${ }^{3}$ e Histoire de Juliette (1801), para indagar sobre sus implicancias filosóficopolíticas, mostrando cómo se establece en dichos textos un diálogo crítico con el contractualismo hobbesiano. En primer lugar, examinamos la relevancia específica de Thomas Hobbes en la crítica que Sade, a través de sus personajes libertinos, realizaría al pensamiento político moderno. En segundo lugar, estudiamos las distintas definiciones que los y las intérpretes de Sade elaboran sobre el isolisme. A continuación, en tercer lugar, analizamos pasajes clave de NJ y $\mathrm{HJ}$ en donde se discute esta categoría (y la familia de términos estrechamente vinculados a ella), intentando elucidar el sentido de sus distintos usos, las argumentaciones en las que se apoyan y las ideas contractualistas que desafiarían. Finalmente, ofrecemos nuestra reflexión conclusiva sobre el recorrido propuesto.

\section{Hobbes, interlocutor filosófico-político de Sade}

El polémico y crítico tratamiento que realizan los personajes libertinos sadeanos respecto del contractualismo y específicamente del iusnaturalismo moderno (Fasso, 1991: 836-842) en las novelas obscenas de Sade no cesa de generar desacuerdos y debates varios entre sus intérpretes. Según Ángel Pelayo GonzálezTorre (2006), el Marqués pretende en sus novelas libertinas utilizar y a la vez ironizar acerca de un modelo teórico vigente durante el período ilustrado, el cual se basa en hacer de la naturaleza y de lo natural el fundamento de toda idea o propuesta moral y política.

En efecto, tal como desarrollaremos en las siguientes secciones del artículo, a lo largo de $\mathrm{NJ}$ y de $\mathrm{HJ}$, muchos de los personajes libertinos desarrollan una concepción de «estado de naturaleza» que se acerca sobremanera a aquella desarrollada por Hobbes ${ }^{4}$, a saber: se trata de un estado de escasez de recursos en

\footnotetext{
${ }^{3}$ Para datar el año de publicación de las obras en cuestión, seguimos a Delon (Sade \& Delon [Ed.], 1990-8) quien editó, anotó e introdujo diversos textos de Sade para la Bibliothèque de la Pléiade (Gallimard). Las citas en idioma (francés) corresponden a la edición de Delon. Utilizaremos las abreviaturas "NJ" y "HJ" para referirnos a La Nouvelle Justine y a Histoire de Juliette respectivamente.

${ }^{4}$ En el catálogo de la biblioteca de Sade confeccionado por Alain Mothu (1995), encontramos que el entonces Marqués poseía un ejemplar del De Cive de Hobbes (Mothu, 1995: 628 [95]), obra que, por otra parte, era una fuente importante en la recepción que los philosophes hicieron del filósofo inglés, como veremos a continuación. En tanto muchas de las
} 
donde cada individuo compite con otros/as por su supervivencia. El estado de naturaleza es descrito así como un estado de guerra permanente, en donde toda estrategia vale para imponerse sobre los demás -el engaño y la fuerza siendo dos de las más recurrentes. La cercanía con Hobbes (y la consiguiente distancia respecto de otros pensadores contractualistas en lo concerniente a su caracterización del estado de naturaleza) no parecería ser casual. Desde nuestro punto de vista, Sade intenta apropiarse críticamente de la concepción hobbesiana de «naturaleza humana", introduciendo diferencias en apariencia mínimas pero que no obstante sirven para desarticular la argumentación que el pensador inglés desarrolla respecto de la legitimidad del pacto social. Estas diferencias, sobre las cuales nos explayaremos más adelante, giran principalmente en torno al temor a la muerte: en Hobbes, esta pasión tiene un alcance y una importancia mucho mayor de la que los personajes libertinos sadeanos están dispuestos a otorgar.

Adicionalmente, la relevancia histórica de Hobbes en lo concerniente a los debates filosófico-políticos dados en Francia durante el período ilustrado no debe subestimarse: el llamado "Hobbisme», tal como lo designa Denis Diderot en su artículo homónimo en la Enciclopedia, despertó durante el siglo XVIII numerosas críticas. Diversos pensadores, entre los que se encuentran por ejemplo Charles Louis de Secondat, barón de Montesquieu ${ }^{5}$ y Jean-Jacques Rousseau, rechazaron la caracterización que el pensador inglés realizó del estado de naturaleza como un estado de guerra permanente, generalmente favoreciendo un panorama más sosegado de la naturaleza humana. Tal como puede observarse en el Discours sur l'origine et les fondements de l'inégalité parmi les hommes $(1755)^{6}$ de Rousseau o en el mencionado artículo «Hobbisme» que aparece en

problemáticas que tratamos en el artículo parecen desarrollarse más extensamente en Leviatán, citaremos mayormente este libro indicando asimismo los pasajes pertinentes del Sobre el ciudadano.

${ }^{5}$ Según Montesquieu, en De l'esprit des lois (1748): «Le désir que Hobbes donne d'abord aux hommes de se subjuguer les uns les autres n'est pas raisonnable. Lidée de l'empire et de la domination est si composée, et dépend de tant d'autres idées, que ce ne serait pas celle qu'il aurait d'abord» (Montesquieu, 1979: 126); «Hobbes atribuye a los hombres, en primer término, el deseo de dominarse los unos a los otros, lo cual no tiene fundamento ya que la idea de imperio y de dominación es tan compleja y depende de tantas otras ideas, que difícilmente podría ser la que tuvieran los hombres en primer lugar» (Montesquieu, 1998: 9). Cf. Mothu (1995: 649 [234]).

${ }^{6}$ Cf. Mothu (1995: 619 [77]). Rousseau pide a sus lectores y lectoras que no crean, tal como propondría Hobbes (según el ginebrino), que el hombre es «naturellement méchant, (...) vicieux parce qu'il ne connaît pas la vertu, [o] qu'il refuse toujours à ses semblables des services qu'il ne croit pas leur devoir» (Rousseau, 2008: 94) [“Naturalmente malo; vicioso, porque no conoce la virtud; que niega siempre a sus semejantes los servicios que cree no deberles» 
el octavo volumen de l'Encyclopédie $e^{7}$ la caracterización del hombre «natural» y/o «incivilizado» usualmente atribuida a Hobbes en la Francia ilustrada del siglo XVIII solía resumirse en la conocida frase del De Cive, "malus est puer robustus». Sade se hace eco de este problemático deslizamiento conceptual que algunos ilustrados franceses realizan, a partir del cual la figura del hombre egoísta hobbesiano en estado de naturaleza es descripta como alguien malvado o "méchant» ${ }^{8}$. Así, al construir sus villanos libertinos, Sade exacerba y radicaliza este egoísmo hobbesiano atribuido al hombre en estado de naturaleza para asegurar la inalienabilidad de su soberanía individual. De esta forma, nace la singular noción sadeana de «isolisme» que estudiaremos a continuación.

\section{Isolisme}

Algunos intérpretes como Alice Laborde (1974), Philippe Roger (1995), Michel Delon (2011) y Jean-Christophe Abramovici (2013) han evocado el

(Rousseau, 2009: 53)]. En principio, Rousseau estaría remitiéndose aquí a la idea hobbesiana de que en estado de naturaleza ninguna acción puede ser, estrictamente hablando, injusta, debido a que la justicia y la propiedad comienzan, según Hobbes, con la constitución de la República (Hobbes, 2007: 143). Hobbes define a la injusticia como el no cumplimiento de un pacto. Ahora bien, en estado de guerra, cuando todavía no ha habido una transferencia de derechos y no se ha establecido un poder coercitivo que obligue a los hombres a cumplir sus pactos, en sentido estricto no sería injusto quien decida no honrarlos pues tiene, en estado de naturaleza, «derecho a todo». Cf. Leviatán, capítulo XV. Rousseau también podría estar refiriéndose a la idea de que «bien» $\mathrm{y}$ «mal» en el estado de naturaleza son la medida de los apetitos y las aversiones de un individuo determinado.

${ }^{7}$ La publicación del octavo volumen había sido prevista para 1758, aunque finalmente se dio en 1765. Thielemann (1951) sostiene que el artículo "Hobbisme» constituía la exposición más completa del sistema de Hobbes en Francia en el siglo XVIII. Sin embargo, este comentador también muestra que, para componerlo, Diderot adaptó el texto que Johan Brucker le había dedicado al filósofo inglés en su Historia Critica Philosophiae, además de tener en cuenta el Dictionnaire historique et critique de Pierre Bayle. El contenido del artículo «Hobbisme» es luego reescrito y discutido por el barón d'Holbach en su Système social (1773), obra que Sade poseía en su biblioteca. Cf. Mothu (1995: 618 [72]).

${ }^{8}$ Rousseau, por ejemplo, articula su crítica a Hobbes de la siguiente manera: «Le méchant, dit-il [Hobbes], est un Enfant robuste; il reste à savoir si l'Homme Sauvage est un Enfant robuste» (Rousseau, 2008: 94). «El malo, dice [Hobbes], es un niño fuerte. Falta saber si el hombre salvaje, es un nińo fuerte» (Rousseau, 2009: 53). En favor de Rousseau, es cierto que Hobbes en el capítulo XIII de Leviatán argumenta que, si bien él considera que un estado de guerra en donde cada hombre es enemigo de cada hombre difícilmente podría haber existido, sugiere que en muchos lugares de América las "gentes salvajes» de este continente viven así (recordemos que Leviatán se publica en 1651). 
concepto de «isolisme», término acuñado por Sade, para referirse al aislamiento existencial que implica la singularidad de cada individuo en las novelas de Sade, similar al «solipsismo» en un sentido moral (Deprun, 1980).

La primera, Alice Laborde, describe el fenómeno del «isolisme» como un sentimiento auténtico que puede ser atribuido tanto al «libertino sádico» como al «hombre normal». En este sentido, ella retoma la categoría de «isolisme agressiff de Jean Deprun (1968), categoría que define como «une sorte d'égoïsme outrancier qui ne connaît aucune borne» (Laborde, 1974: 158) ${ }^{9}$, para ampliarla y mostrar que el isolisme se aplica asimismo a personajes como Justine. Laborde utiliza el término «isolisme» también para referirse al aislamiento espacial que suponen las grandes fortalezas libertinas y al estado de alienación y de soledad de las víctimas encerradas en ellas. Al mismo tiempo, el goce también es un factor aislante para los «libertins sadiques», porque refrenda la unidad del cuerpo propio como sujeto de sensaciones, contribuyendo a renegar de la reciprocidad, según Laborde. Pero, además, este aislamiento se reforzaría a través de la progresiva insensibilidad que va adquiriendo el personaje libertino. Por otro lado, Laborde también considera que el aislamiento o isolement de esta clase de subjetividades típicas de las novelas obscenas de Sade tiene que ver con que estos se consideran por fuera de las normas de la sociedad en la que viven (Laborde, 1974: 161). Por lo tanto, Laborde concluye que el isolement en la obra de Sade supone «Une prise de conscience métaphysique des limites inhérentes à la condition humaine, sa réalisation engendrant chez le personnage sadien, et plus particulièrement chez le libertin sadique, un état d'âme tragique, source de lyrisme» (Laborde, 1974: $163)^{10}$.

Philippe Roger, por su parte, repara en la evolución del sentido del término entre NJ y HJ. La primera aparición de la palabra «isolisme» surge en una descripción del penoso estado de Justine, rechazada por todas las personas a las que acudía para pedir ayuda. Roger destaca el registro «sociológico» de esta temprana significación de «isolisme». En HJ, no obstante, este término adoptará un nuevo sentido, de acuerdo con este intérprete; ya no designará la soledad o la falta de asistencia en la que se encuentra Justine, sino que se transformará

\footnotetext{
${ }^{9}$ Acompañamos a continuación una traducción al español de la frase. A menos que se indique lo contrario, las traducciones son propias: «Una suerte de egoísmo extravagante que no conoce ningún límite».

10 «Una toma de consciencia metafísica de los límites inherentes a la condición humana, su realización que engendra en el personaje sadeano, y particularmente en el libertino sádico, un estado anímico trágico, fuente de lirismo».
} 
en una tesis filosófica sobre la condición humana y la soberanía que, a nivel individual, resulta constitutiva de cada personaje dentro de las novelas de Sade. Por eso, Roger afirma que «The sovereignty of Sadean man is not inalienable; it is inexpiable, giving respite neither to the individual nor to the would-be societies» (Roger, 1995: 89) ${ }^{11}$.

Según Delon (2011: 133-134), el término «isolisme» prevaleció sobre los de "égoïsme» $\mathrm{y}$ "nihilisme». "Isolement» se dice aquí en un sentido metafísico; se trata de un subjetivismo individualista radical que excede cualquier instanciación empírica contingente de la subjetividad. En cuanto al término «nihilisme», este habría surgido justamente en el siglo XVIII e inclusive aparece contemporáneamente al desarrollo y publicación de las novelas libertinas del (para entonces) ex Marqués. De hecho, Lester Crocker (1963), por ejemplo, ha argumentado que las cosmovisiones materialistas y ateas que estos personajes proponen traen como consecuencia el «ocaso nihilista» de las Luces, (utilizando «nihilismo» en un sentido post-nietzscheano).

Tal como destaca Abramovici, el corolario del aislamiento en las subjetividades libertinas sadeanas es la apatía, esto es: aquello que le permite al libertino conectarse con esa diversidad monstruosa integral que se busca alcanzar en la experimentación sexual. Justamente en tanto materialistas, los libertinos y libertinas defienden un determinismo sensualista enmarcado en un fuerte subjetivismo individualista. La preeminencia del cuerpo como subjetividad forja, para cada individuo, una experiencia propia y por ende única del mundo. Como corolario, esto desemboca en el aislamiento existencial del sí-mismo. En este sentido, el uso de la razón no decanta en el reconocimiento del otro como un igual, sino que esta se torna un mero instrumento de cálculo para el goce.

A continuación, relevaremos las principales apariciones y matices del isolisme que encontramos en $\mathrm{NJ}$ y en $\mathrm{HJ}$.

\footnotetext{
${ }^{11}$ «La soberanía del hombre sadeano no es inalienable; es inexpiable, y no da tregua ni al individuo ni a las supuestas sociedades».
} 


\subsection{NJ}

La primera de las apariciones del término «isolisme» tiene a Justine como protagonista y refiere al rechazo social generalizado que sufre por no integrarse y ceder ante el sistema mercantil que la empuja constantemente a prostituir su cuerpo (lo que Roger identifica como el registro sociológico del término). Se trata del episodio en donde ella asiste a una Iglesia para pedir ayuda por su condición de huérfana, no contando con otras personas a las cuales acudir. El cura le ofrece "trabajo» a cambio de alimentos, pero le aclara a la joven que ella debe estar dispuesta a "faire le gros ouvrage» ${ }^{12}$. Justine lo rechaza...

LE SERVITEUR DE CHRIST, honteux d'être dévoilé, se lève en colère; il appelle sa nièce et sa servante:

- Chassez-moi cette petite coquine, leur crie-t-il; vous n'imagineriez pas ce qu'elle vient de me proposer... Tant de vices à cet âge!... et à un homme comme moi!... Qu'elle sorte... qu'elle sorte, ou je la fais arrêter dans l'instant!...

Et la malheureuse Justine, repoussée, calomniée, insultée dès le premier jour qu'elle est condamnée à l'ISOLISME (...) s'y livre à des larmes d'autant plus amères, qu'elle est naturellement très sensible, et que sa fierté vient d'être cruellement compromise (Sade, 1995: 401) ${ }^{13}$.

\footnotetext{
${ }^{12}$ Un eufemismo para referirse a la esclavitud sexual, también utilizado en Thérèse philosophe (Trousson [Ed.], 2001).

${ }^{13}$ «EL SERVIDOR DE CRISTO, avergonzado al ser descubierto, se levanta en cólera, llama a su sobrina y su sirviente:

-Sáqueme a esta pequeña atrevida, le grita; no se imaginaría lo que ella acaba de proponerme... ¡Tantos vicios a esta edad! ... ¡ 氵 a un hombre como yo! ... Que salga... ¡que se vaya, o la hago arrestar al instante!

Y la desdichada Justine, mancillada, calumniada, insultada desde el primer día que ha sido condenada al AISLAMIENTO (...) se libra a las lágrimas tanto más amargas por cuanto ella es naturalmente sensible, y su orgullo viene de ser cruelmente comprometido». Respetamos, al transcribir las citas de Sade, las mayúsculas y cursivas originales.
} 
En esta escena, perteneciente a los comienzos de la narración de la vida de la virtuosa joven, el aislamiento de Justine remite al rechazo que esta sufre por parte de los miembros de esta comunidad religiosa. Este vilipendio se genera a partir de que una figura de autoridad, como el cura señala a Justine como pecadora e incita a los demás feligreses a imitarlo. En este sentido, la historia de Justine podría pensarse como una repetición episódica de esta misma distribución de fuerzas, a saber: un grupo de personajes que actúa en consonancia para someter, abusar o expulsar a nuestra virtuosa heroína. Es menester notar además que la acción colectiva (libertina) es lo que generalmente la salva de perder la vida, esto es: aliarse a un grupo de criminales, aunque más no sea fortuita y/o pasivamente.

El siguiente pasaje nos permite adentrarnos en una de las primeras formulaciones libertinas del concepto de «isolisme». En efecto, se trata de una conversación entre la Dubois, jefa de una banda de maleantes y consumada libertina, que se encontraba en la misma prisión que Justine, ambas a días de ser llevadas hacia el cadalso. La Dubois comparte con Justine el plan de su escape: sus secuaces generarán un incendio que les permitirá escabullirse de allí, evitando así ser ejecutadas. La libertina le explica a la piadosa joven que efectivamente muchas personas inocentes morirán a causa de dicho incendio, pero que sus vidas no la preocupan en lo más mínimo:

Je ne connais pas, moi, ce fil de fraternité ridicule qu'établissent chez les hommes la faiblesse et la superstition. Soyons isolés, ma fille, comme nous a fait naître la nature: lui voyons-nous jamais lier un homme à un homme? Si quelquefois nos besoins nous rapprochent, séparons-nous dès que nos intérêts l'exigent, parce que l'égoïsme est la première des lois de la nature, la plus juste, la plus sacrée, sans doute. N'apercevons jamais dans les autres que des individus faits pour nos passions ou pour nos caprices. Déguisons-nous, si nous sommes les plus faibles; usons de tous nos droits comme les animaux, si nous sommes les plus forts (Sade, 1995: 431) ${ }^{14}$.

\footnotetext{
${ }_{14}$ «Yo no conozco, por mi parte, este ridículo hilo de fraternidad que establecen entre los hombres la debilidad y la superstición. Estemos aislados, mi muchacha, como nos ha hecho nacer la naturaleza: ¿acaso la vemos alguna vez ligar un hombre a otro hombre? Si a veces nuestras necesidades nos acercan, separémonos desde que nuestros intereses lo exigen, porque el egoísmo es la primera de las leyes de la naturaleza, la más justa, la más sagrada, sin duda. No percibamos jamás en los otros más que individuos hechos para nuestras pasiones o para
} 
A diferencia de lo que sostiene Roger, el sentido filosófico-político del isolisme aparece tempranamente en NJ, en este extracto del diálogo entre la Dubois y Justine. La invitación de la Dubois a «aislarse» no implica ahogarse en la soledad individualizadora a la que la ignominia social condena a Justine. Por el contrario, se trata de un aislamiento paradójicamente grupal, en el que un grupo de subjetividades que comparten un mismo interés se unen, aunque más no sea momentáneamente, para lograr un mismo objetivo. La Dubois no apunta a inspirar en Justine cierta "solidaridad femenina» (de otra forma, debería decir «Soyons isolées», tratándose de dos mujeres); el imperativo «Soyons isolés» expresa más bien una invitación retórica que se dirigiría a todos los seres humanos. Mientras que, según la Dubois, la idea de "fraternidad» proviene de las absurdas imposiciones de la "civilización», tanto en su arista secular como religiosa, la naturaleza, opuesta a toda esta parafernalia ideológica, impondría al egoísmo como su ley primera. Este egoísmo implica, al mismo tiempo, una precisa evaluación de las propias fuerzas del individuo y de las de otros varones y mujeres a su alrededor, que deberían ser considerados, según la Dubois, meramente como medios para satisfacer los propios deseos. Se introduce ya aquí, en esta temprana instancia, la diferencia entre «los más fuertes» y «los más débiles», asociada a la caracterización de las relaciones humanas en el «estado de naturaleza» (particularmente del contractualismo hobbesiano).

Tal como surge de la lectura del Leviatán (XIII), todos los individuos en «estado de naturaleza» tienen capacidades y recursos diferentes que los pondrían, en principio, en igualdad de condiciones; un hombre de mucha fuerza física podría ser asesinado mientras duerme por otro, cuya "perspicacia» compense en alguna medida sus magras habilidades para pelear con el cuerpo. Hobbes apunta a desarticular o neutralizar las diferencias entre «los más fuertes» y «los más débiles», para demostrar la racionalidad del acto de pactar y de consentir la creación de una persona artificial, la República ${ }^{15}$, que concentre en sí toda la fuerza de la espada siendo la única autorizada a impartir justicia, constituyendo un «poder común capaz de defenderlos [a los/as pactantes] de la invasión extranjera y las injurias de unos a otros» (Hobbes, 2007: 166).

nuestros caprichos. Camuflémonos, si somos los más débiles; hagamos uso de todos nuestros derechos como los animales, si somos los más fuertes».

${ }^{15}$ Hobbes incluye también su denominación latina, civitas, y la representa como liderada por un hombre o asamblea de hombres que concentra toda la fuerza y el poder de los pactantes y que reduce todas sus voluntades a una única voluntad (Hobbes, 2007: 166). Cf. De Cive, V, IX; X. 
La libertina Dubois, por el contrario, parecería proponer la aceptación o la resignación ante estas diferencias de talentos naturales, aunque sugiriendo a los aparentemente menos aventajados ciertos recursos que les permitirían perpetuarse y sobrevivir. Uno de ellos sería, como mostramos anteriormente, asociarse entre sí cuando existen intereses comunes (y solo mientras dure dicha coincidencia); otra forma de "dar pelea» sería adoptar la táctica del disfraz y la disimulación, frecuentes en «ambientes civilizados». Se vislumbra en este pasaje la polarización, común a otros personajes libertinos también, entre los «más débiles», quienes se valdrían de las alianzas (y, yendo más lejos, de las instituciones y el Estado mismo) como método de protección y subsistencia, y los «más fuertes», signados por su potencia basada presumiblemente en el puro dominio de ciertas regiones a base de fuerza física.

Una vez que Justine y la Dubois efectivamente escapan, la libertina intenta entonces convencer a Justine de que se una a su banda, y de que sea una cómplice más de sus fechorías. Le sugiere además prostituirse, a fin de adquirir dinero y poder. Pero la piadosa muchacha se rehúsa y se desata un debate entre ellas y el hermano de la Dubois, también miembro de la banda, a quien llaman Coeurde-Fer. Al elogio del isolisme que realiza la Dubois, Justine opone la siguiente contra-argumentación:

Comment voulez-vous que ne périsse pas celui qui, par un aveugle égoïsme, voudra lutter seul contre la coalition des intérêts des autres? La société n'est-elle pas autorisée à ne jamais souffrir dans son sein celui qui se déclare contre elle? et l'individu qui s'isole peut-il lutter contre tous? peut-il se flatter d'être heureux et tranquille, si n'acceptant pas le pacte social, il ne consent pas à céder un peu de son bonheur pour en assurer le reste? (Sade, 1995: 449) ${ }^{16}$.

\footnotetext{
16 «¿Cómo quiere usted que no perezca aquel que, por un ciego egoísmo, querrá luchar solo contra la coalición de intereses de los demás? La sociedad ¿̨no está ella autorizada a jamás sufrir en su seno a aquel que se declara en su contra? Y el individuo que se aísla ¿puede luchar contra todos? ¿puede vanagloriarse de estar feliz y tranquilo, si no aceptando el pacto social, no consiente a ceder un poco de su felicidad para asegurar la del resto?».
} 
Justine intenta refutar a la Dubois mostrándole que el aislamiento pone al individuo en una posición sumamente desventajosa, ya que toda la sociedad estaría en su contra. La muchacha intenta de alguna forma «hablar» el lenguaje de la libertina, haciendo hincapié en la inconveniencia del isolisme o, tal como lo expresa ella misma, de cierto «egoísmo ciego». Justine representa la situación del individuo aislado como un enfrentamiento con la sociedad entera, de manera tal de subrayar la inequidad de fuerzas entre este y el conjunto social en su totalidad. De todas maneras, la hermana de Juliette incorpora a su argumentación el lenguaje del contractualismo y de la filosofía política, cuando supone que la sociedad está «autorizada» a tomar medidas en contra de los que se declaran sus enemigos y cuando asume que el individuo aislado no acepta el pacto social. Coeur-de-Fer tiene una respuesta para las objeciones de Justine, que se basan en señalar que pactar y someterse al Soberano no siempre y no para todo el mundo es algo conveniente:

Je ne blâme point la proposition de ce pacte; mais je soutiens qu'il existe deux sortes d'individus qui ne durent jamais s'y soumettre: ceux qui, se sentant les plus forts, n’avaient pas besoin de rien céder pour être heureux; et ceux qui, étant les plus faibles, se trouvaient céder infiniment plus qu'on ne leur assurait. Cependant, la société n'est composée que d'êtres faibles et d'êtres forts. Or, si le pacte doit déplaire aux forts et aux faibles, il sien fallait donc de beaucoup quil convînt à la société; et l'état de guerre, qui existait avant, devait se trouver infiniment préférable, puisqu'il laissait à chacun le libre exercice de ses forces et de son industrie, dont il se trouvait privé par le pacte injuste d'une société enlevant toujours trop à l'un, et n'accordant jamais assez à l'autre (Sade, 1995: 451) ${ }^{17}$.

\footnotetext{
17 «Yo no censuro la proposición de este pacto; pero sostengo que existen dos suertes de individuos que no debieron jamás someterse a él: aquellos que, sintiéndose los más fuertes, no tenían necesidad de ceder en nada para ser felices; y aquellos que, siendo los más débiles, se encontraban cediendo infinitamente más que lo que se les aseguraba. Sin embargo, la sociedad no está compuesta sino de seres débiles y de seres fuertes. Ahora bien, si el pacto ha de disgustar a los fuertes y a los débiles, estaba entonces muy lejos de convenir a la sociedad; y el estado de guerra, que existía antes, debía encontrarse infinitamente más preferible, puesto que dejaba a cada uno el libre ejercicio de sus fuerzas y de su industria, del cual se encontraba privado por el pacto injusto de una sociedad que quita siempre demasiado a uno, nunca acordando bastante al otro».
} 
Coeur-de-Fer propone aquí dos perfiles de individuos para los cuales sería irracional pactar: aquellos que se encuentran en los extremos de la gradación de fuerza: los más fuertes y los más débiles. Los primeros no tendrían motivo alguno para transferir o abandonar sus derechos, es decir, «soltar las armas», relegando su bienestar para sacrificarse por otros. Los segundos, no habiendo sido dotados de gran fuerza, bienes o armas en general, no tendrían sino su libertad para perder, por lo que no habrían de alienarla en un pacto. El argumento de Coeur-de-Fer supone que ni para unos ni para otros la integración consentida a la sociedad civil mejoraría su calidad de vida. Aquí podría vislumbrarse cierto uso de la paradoja del montón o «sorites» ${ }^{18}$ (nótese el desplazamiento desde «les plus forts/ faibles» hacia "les forts/faibles»), pues ¿quiénes serían esos «más fuertes» o "más débiles» de los que habla Coeur-de-Fer? El bandido parece extender esos puntos extremos, «le plus faible», "le plus fort», para generar una indistinción entre los distintos grados de "poderío» o "fuerza» de cada individuo dentro de la sociedad. El sorites justamente funciona con estos conceptos ambiguos, cuyos límites no son fácilmente determinables; a través de la inducción, va estirándolos.

En todo caso, aun cuando Coeur-de-Fer no logre probar que el pacto no conviene a ningún individuo, ya sea fuerte o débil, sí demarca estas dos figuras para quienes respetar los acuerdos sometiéndose a la ley del Soberano reportaría menos beneficios que pérdidas. Ahora bien, su tesis de que, en ciertas circunstancias o para ciertas personas, el estado de guerra es preferible a la paz parece darse de bruces con la posición hobbesiana, pero al mismo tiempo parece surgir de ella, suponiendo, tal como hace el filósofo materialista inglés, que lo que le da sentido al pacto es justamente la idea de que se trata efectivamente de una estrategia de supervivencia tanto individual como colectiva. Hobbes entiende que existen tanto pasiones (por ejemplo, el temor a la muerte) como preceptos de la razón («leyes de naturaleza») que orientan al hombre hacia la preservación

${ }_{18}$ Transcribimos la formulación de Aspasio del argumento «sorites» en su comentario a la Ética Nicomaquea de Aristóteles (Sobre la Ética Nicomaquea, 56.25-32; 57.3-7 [Heylbut]): "¿Qué cantidad posee el rico? Si alguien postulara que el rico posee diez talentos, se le preguntará: “ ¿y si le falta una dracma ya no es rico? ¿y si le faltan dos?”. Pues es imposible determinar con precisión este tipo de cosas, dado que son sensibles, es decir si es rico o pobre. $Y$ en el caso del pelado se puede preguntar: “¡alguien se vuelve pelado por un pelo? ¿y por dos? ¿y por tres?", de donde toman su nombre los argumentos, es decir los argumentos "pelados". Y en el caso del montón se pregunta lo mismo, si el montón se disminuye en un grano de trigo, o dos y así sucesivamente. Y no es posible decir cuándo comienza a no haber montón porque ninguna de las cosas perceptibles se puede captar con precisión, sino de forma aproximada y en general» (Mársico, 2013: 159). Diógenes Laercio atribuye su autoría a Eubúlides de Mégara (Mársico, 2013: 142). 
de su vida y que dicha preservación no puede darse sino en la paz. El pacto social consiste, en cierto sentido, en el compromiso a abstenerse de ser hostil con todos los demás pactantes. Más allá de ello, Hobbes explica que, en determinadas circunstancias, cuando por ejemplo no se da la unanimidad necesaria que exige el pacto, no sería racional «abandonar las armas»:

Quien fuera modesto y tratable, y cumpliese todo cuanto prometiere, en tiempo y lugar donde ningún otro hombre lo hiciese, no haría sino hacerse presa de otros y procurar su propia y cierta ruina, contra la base de toda ley de naturaleza, que tiende a la preservación de la naturaleza. Y, además, aquel que teniendo suficiente seguridad de que otros observarán las mismas leyes con respecto a él, no las observe él mismo, no busca la paz, sino la guerra. (...) Las leyes de naturaleza son inmutables y eternas, pues la injusticia, la ingratitud, la arrogancia, el orgullo, la iniquidad, el favoritismo de personas y demás no pueden nunca hacerse legítimos, porque no puede ser que la guerra preserve la vida y la paz la destruya (Hobbes, 2007: 153-4) ${ }^{19}$.

Cœur-de-Fer parecería partir de las mismas premisas aunque arribando a una conclusión algo distinta, a saber: que la guerra sí preserva la vida (en ciertos casos) y que, al menos, si no lo hace, le otorga al individuo la posibilidad de vivir soberanamente. Por eso, continúa este personaje:

L'être vraiment sage est celui qui, au hasard de reprendre l'état de guerre qui régnait avant le pacte, se déchaîne impérieusement contre ce pacte, le viole autant quil le peut, certain que ce qu'il retirera de ces lésions sera toujours supérieur à ce qu'il pourra perdre, s'il se trouve le plus faible; car il l'était de même en respectant le pacte; il peut devenir le plus fort en le violant; et, si les lois le ramènent à la classe dont il a voulu sortir, le pis-aller est qu'il perdra la vie, ce qui est un malheur infiniment moins grand que celui d'exister dans l'opprobre et dans la misère (Sade, 1995: 451)20.

\footnotetext{
${ }^{19}$ Cf. De Cive, II, II: «La primera y fundamental ley de naturaleza es que debe buscarse la paz allí donde pueda encontrarse; y donde no, proveernos de medios y ayudas para hacer la guerra» (Hobbes, 2000: 68).

${ }_{20}$ «El ser verdaderamente sabio es aquel que, ante la posibilidad [el azar] de retomar el estado de guerra que reinaba antes del pacto, se desentiende imperiosamente de este pacto, lo viola
} 
Para aquel que no tiene nada que perder, excepto su vida, arriesgarse a cometer acciones criminales que lo desvinculen del pacto es una oportunidad para establecerse como «el más fuerte». Hobbes, a diferencia de Coeur-de-Fer, hace hincapié en el temor a la muerte como una de las pasiones más movilizadoras en el ser humano, temor que en el discurso del libertino se subestima o pretende neutralizarse. En este sentido, el espíritu de la obra del inglés no parecería concordar con la idea de que es preferible morir antes que vivir una vida miserable; si fuese así, el poder soberano alcanzado por la fuerza natural, es decir, por adquisición ${ }^{21}$, no tendría razón de ser.

\subsection{HJ}

Debemos tener en cuenta que Cour-de-Fer está dirigiéndose a la piadosa Justine, que, en tanto se resiste a prostituirse, desamparada, huérfana, sin ofertas de trabajo, no puede proveerse su sustento y es por ello pobre. La argumentación del libertino se orienta a persuadir a la joven de que se una a su banda criminal. Ahora bien, cuando el público varía, también varía la formulación de los razonamientos en contra de la conveniencia y la racionalidad del pacto social. Esto puede observarse, por ejemplo, en HJ en la disertación de Noirceuil, tutor libertino de Juliette. Él sostiene que:

Toutes les créatures naissent isolées et sans aucun besoin les unes des autres: laissez les hommes dans l'état naturel, ne les civilisez point, et chacun trouvera sa nourriture, sa subsistance, sans avoir besoin de son semblable. Les forts pourvoiront à leur vie sans nécessité d'assistance; les faibles seuls en auront peut-être besoin; mais ces faibles nous sont asservis par la main de

\footnotetext{
tanto como puede, seguro de que lo que obtendrá de estas lesiones será siempre superior a lo que podrá perder, si se halla [a sí mismo] el más débil; pues igualmente lo era respetando el pacto; él puede devenir el más fuerte al violarlo; y si las leyes lo devuelven a la clase de la cual ha querido salir, lo peor [que puede pasar] es que perderá la vida, lo que es una desgracia infinitamente menos grande que la de existir en el oprobio y en la miseria».

${ }^{21}$ Según Hobbes: "Así sucede cuando un hombre hace que sus hijos y los hijos de éstos se sometan a su gobierno como siendo capaz de destruirlos si rehúsan. $\mathrm{O}$ cuando mediante guerra somete a sus enemigos a su voluntad, dándoles la vida con esa condición» (Hobbes, 2007: 167). Cf. De Cive, I, XIV \& II, VIII.
} 
la nature; elle nous les donne, elle nous les sacrifie: leur état nous le prouve; donc le plus fort pourra, tant qu'il voudra, se servir du faible (Sade, 1998: $335)^{22}$.

Dirigido hacia la elite de la clase más acomodada, el discurso de Noirceuil propone que no existan mediaciones que aminoren las diferencias entre los fuertes y los débiles, ya que, básicamente, estos últimos son ofrecidos a los primeros por la naturaleza misma. Coeur-de-Fer ya lo adelantaba: ¿por qué razón un hombre en la cima del poder alienaría su soberanía para asistir a otros, poniendo en peligro o disminuyendo su propio bienestar?

Ahora bien, la caracterización del aislamiento que se sigue de las palabras de Noirceuil parecería significar, por otro lado, que en realidad los vínculos afectivos que desarrollan los seres humanos a lo largo de la vida son arbitrarios, espurios y prescindibles. Así, este libertino parece argumentar en favor de la actualidad (a diferencia de la latencia) de un estado de naturaleza exacerbadamente hobbesiano, en el cual las promesas y los pactos no son respaldados por una autoridad constituida. Cada individuo está entonces solo frente a los otros.

Le prétendu fil de fraternité ne peut donc avoir été imaginé que par le faible; car il n'est pas naturel que le plus fort, qui n'avait besoin de rien, ait pu lui donner l'existence: pour assouplir le plus faible, sa force seule lui devenait nécessaire, mais nullement ce fil, qui, dès lors, n'est que l'ouvrage du faible, et n'est plus fondé que sur un raisonnement aussi futile que le serait celui de l'agneau au loup: Vous ne devez pas me manger, car j'ai quatre pieds comme vous (Sade, 1998: 336) ${ }^{23}$.

\footnotetext{
${ }^{22}$ «Todas las criaturas nacen aisladas y sin ninguna necesidad las unas de las otras: dejad a los hombres en el estado natural, no los civilicéis, y cada uno encontrará su alimento, su subsistencia, sin necesitar a su semejante. Los fuertes se proveerán sin necesidad de asistencia; quizás sean los débiles los únicos que tendrán tal necesidad; pero estos débiles nos han sido sometidos por la mano de la naturaleza; nos los da; nos los sacrifica: su condición lo prueba; por lo tanto, el más fuerte podrá servirse del débil, en la medida que pueda» (Sade, 2009: 142).

${ }^{23}$ «Así pues, el pretendido hilo de fraternidad no puede haber sido imaginado más que por el débil; porque no es natural que el más fuerte, que no necesita nada, haya podido darle
} 
Según Noirceuil, los «naturalmente débiles» desarrollan, tal como veíamos en la argumentación de Coeur-de-Fer, estrategias para protegerse de los más fuertes y sobrevivir. El pacto social y la moral de la virtud que este supondría serían instrumentos ideológicos de los que estos se servirían para aplacar las ventajas de los «más fuertes», haciéndoles creer que su bienestar consiste en vivir una vida pacífica, sin imponerse sobre los demás. Ahora bien, uno podría pensar que la misma disertación de Noirceuil funciona como un dispositivo de este tipo, pero que, a la inversa, apunta a fortalecer las inclinaciones crueles de los más poderosos. Se trata, en este sentido, de una parte integral de la formación libertina de Juliette y quizás también de la de los lectores y las lectoras.

El mismo Ghigi (el jefe de la policía romana) nos ofrece otra expresión de esta «defensa» o alabanza del estado de naturaleza. En este caso, lo paradójico es que se trata de alguien que está a cargo del aparato represivo de toda una región y que a la vez sostiene la idea de que los hombres harían una mejor elección (tendrían más chances de vivir felizmente) si no se sometiesen al «yugo absurdo de las leyes»:

Rendus à l'état de nature, les hommes, je le soutiens, seraient plus heureux qu'ils ne peuvent l'être sous le joug absurde des lois. Je ne veux pas que l'homme renonce à aucune portion de sa force et de sa puissance. (...) J'aime mieux être opprimé par mon voisin, que je puis opprimer à mon tour, que de l'être par la loi, contre laquelle je n'ai nulle puissance. Les passions de mon voisin sont infiniment moins à craindre que l'injustice de la loi, car les passions de ce voisin sont contenues par les miennes, au lieu que rien n'arrête, rien ne contraint les injustices de la loi (Sade, 1998: 837) ${ }^{24}$.

existencia: para someter al débil, sólo necesita su fuerza, pero de ninguna manera ese hilo que, desde ese momento, únicamente puede ser obra del débil, y que no se basa más que en un razonamiento tan fútil como lo sería el del cordero al lobo: "No debéis comerme, porque tengo cuatro patas como vos"» (Sade, 2009: 143).

24 «Sostengo que los hombres serían más felices vueltos al estado natural de lo que pueden serlo bajo el absurdo yugo de las leyes. No quiero que el hombre renuncie a una parte de su fuerza (...). Prefiero estar oprimido por mi vecino, al que a mi vez puedo oprimir, que por la ley, contra la que no tengo ningún poder. Las pasiones de mi vecino son infinitamente menos temibles que la injusticia de la ley, porque las pasiones de dicho vecino están reprimidas por las mías, mientras que nada detiene, nada se opone a las injusticias de la ley» (Sade, 2009: 586). 
Así, vemos que este personaje rechaza teoréticamente una premisa clave de la vasta tradición política moderna contractualista, esto es: que es racional renunciar al derecho natural de impartir justicia por mano propia para asociarse con otros y ceder el poder coercitivo a una instancia o persona artificial única. Ghigi evoca aquí, no obstante, cierta imagen que sitúa al individuo aislado en un espacio; al utilizar la palabra "voisin", el conflicto entre uno y otro individuo se territorializaría. Observemos, en este sentido, una formulación posterior de esta defensa de la preeminencia y la superioridad del estado de naturaleza respecto de la vida «en sociedad» o "civilizada» por parte de otro libertino italiano, Cornaro.

Abandonnez l'homme à la nature, elle le conduira beaucoup mieux que vos lois. Détruisez surtout ces vastes cités, où l'entassement des vices vous contraint à des lois répressives. Quelle nécessité y a-t-il que l'homme vive en société? Rendez-le au sein des agrestes forêts qui le virent naître, et laissez-lui faire là tout ce qui pourra lui plaire: ses crimes alors, aussi isolés que lui, n'auront plus nul inconvénient, et vos freins deviendront inutiles. L'homme sauvage ne connaît que deux besoins: celui de foutre, et celui de manger; tous deux lui viennent de la nature: rien de ce qu'il fera, pour parvenir à l'un ou l'autre de ces besoins, ne saurait être criminel. Tout ce qui fait naître en lui des passions différentes n'est dû qu’à la civilisation et la société. Or, dès que ces nouveaux délits ne sont le fruit que des circonstances, qu'ils deviennent inhérents à la manière d'être de l'homme social, de quel droit, je vous prie, les lui reprocherez-vous? (Sade, 1998: 1192-3) ${ }^{25}$.

25 «Abandonad el hombre a la naturaleza, ella lo conducirá mucho mejor que vuestras leyes. Sobre todo, destruid esas vastas ciudades donde la saturación de vicios os obligan a leyes represivas. ¿Qué necesidad hay de que el hombre viva en sociedad? Devolvedle al corazón de los agrestes bosques que lo vieron nacer, y dejadle que haga allí todo lo que le venga en gana: entonces sus crímenes, tan aislados como él, no tendrán ninguna consecuencia y vuestros frenos ya no serán necesarios. El hombre salvaje sólo conoce dos necesidades: la de joder y la de comer; las dos proceden de la naturaleza: nada de lo que haga para satisfacer ambas necesidades puede ser criminal. Todo lo que hace nacer en él pasiones diferentes se debe únicamente a la civilización y a la sociedad. Ahora bien, dado que esos nuevos delitos no son sino un producto de las circunstancias, inherentes, por tanto, a la manera de ser del hombre social, ¿con qué derecho, por favor, se los reprocháis?» (Sade, 2009: 905). 
En este fragmento que recoge la opinión de Cornaro directamente se espacializa la diferencia entre «naturaleza»y «civilización». El estado de naturaleza equivale aquí a la vida en los bosques, lejos de los centros urbanos, en donde la proximidad de unos y otros lleva a la acumulación de los vicios y por ende al establecimiento de «leyes represivas». En el bosque, por el contrario, el hombre solo se ocuparía de colmar sus necesidades básicas: la alimentación y el sexo, según Cornaro. En tanto la sociedad y la civilización serían causales de su "corrupción», es decir, de sus inclinaciones delictivas, Cornaro descarga así al «hombre social» de responsabilidad.

\section{Conclusión}

Una de las conclusiones que se siguen de las disertaciones estudiadas de los/as libertinos/as es que si el/la "más fuerte», dotado/a de ferocidad y poder, no tiene razones sólidas para someterse a los designios de una voluntad común que lo/la une e iguala a los/las "más débiles», entonces no debe desistir de preservar su soberanía, no debe «soltar las armas». De hecho, la concepción sadeana de soberanía «aislacionista» (esto es: a nivel individual) estaría inspirada en Hobbes, teniendo en cuenta que el Soberano es, para él, el único que no abandona o transfiere sus derechos y por lo tanto continúa "portando armas» en ese estado de guerra que es el estado de naturaleza hobbesiano. Por lo tanto, en su ficcionalización de dicho estado, Sade parecería sugerir a sus lectores y lectoras la posibilidad de comprender al libertinaje, tal como aparece en sus novelas, como un estado de soberanía que no se encuentra sujeto a ninguna ley: "princeps legibus solutus».

Ahora bien, la disposición de los argumentos filosóficos contra Hobbes dentro de la trama ficcional de la novela hace evidente, desde nuestro punto de vista, que la cuestión del formato que Sade eligió para organizar tales diálogos filosóficos no resulta una cuestión indiferente para nuestro análisis. ¿Acaso existe una única voz en $\mathrm{HJ}$ y HJ que exprese fehacientemente «la propuesta filosóficopolítica de Sade»? Desde nuestra perspectiva, la representación y personificación de ciertas teorías filosóficas en el marco de una narración parecería indicarnos justamente que difícilmente podríamos responder afirmativamente a tal interrogante. Por un lado, si bien en este artículo nos hemos concentrado en el pensamiento de Hobbes, existen a nuestro entender otros interlocutores filosóficos contractualistas a los que Sade estaría intentando reescribir, parodiar 
y/o criticar, como Jean-Jacques Rousseau (un estudio pormenorizado de la relación Sade-Rousseau en su arista filosófico-política excede en mucho el alcance de este artículo). Por otro lado, una revisión de la correspondencia de Sade, junto con la de otros textos que redactó, particularmente aquellos elaborados en sus años de libertad en el período revolucionario pre-termidoreano (1790-3), nos revela que este autor estuvo lejos de sostener una posición política unívoca a lo largo de su vida (Fink, 1989; Candler Hayes, 1989).

Sin embargo, a pesar de que los personajes libertinos se dirigen a un público distinto y provienen de circunstancias vitales distintas, parecen seguir una misma línea teórica en lo concerniente al aislacionismo examinado en su sentido filosófico-político, esto es: la «defensa» o «alabanza» a la noción de estado de naturaleza. Esta defensa pregonaría cierta «apoliticidad», desde la cual se intenta persuadir al lector o a la lectora de que el libertinaje no pactante constituye la elección de vida más racional que puede hacerse. Supone, a la vez, cierta instrumentalización de la política, tal como observa Schwarzböck (2001:108), cuyo único fin para los/as libertinos/as pasa a ser garantizar la provisión de víctimas y la impunidad del procedimiento. Si examinamos la argumentación de González-Torre (2006) sobre este punto, vemos que el autor oscila entre dos posturas. Por un lado, él sostiene que Sade reivindica la violencia, a la cual considera natural y que, según el Marqués, «Lejos de compensar las desigualdades naturales, como se pretende sostener, la ley y el derecho acabarían por mantener y consolidar esas desigualdades» (GonzálezTorre, 2006: 89). Por otro lado, no obstante, este intérprete observa que existe una ambigüedad inherente a la escritura sadeana: si Sade verdaderamente cree en lo que sus personajes predican o si busca simplemente ridiculizar ciertos principios caros a la Ilustración, es, según el comentador, «un punto discutible» (2006: 57) -o bien, podríamos agregar nosotros, un punto indecidible. 


\section{Bibliografía}

Abramovici, Jean-Christophe (2013). Encre de sang. Sade écrivain, Paris: Garnier.

Candler Hayes, Julie (1989). “Aristocrate ou démocrate? Vous me le direz': Sade's Political Pamphlets”. Eighteenth-Century Studies Vol. 23/1, pp. 24-41.

Crocker, Lester (1963). Nature and Culture: Ethical Thought in the French Enlightenment, Baltimore: John Hopkins University Press.

Delon, Michel (2011). Le principe de délicatesse. Libertinage et mélancolie au XVIIIe siècle, Paris: Albin Michel.

Deprun, Jean (1980). "Sade et le rationalisme des Lumières". Raison présente Vol. 55, pp. 17-29.

- (1968). Le Marquis de Sade, Paris: Armand Colin.

Fasso, Guido (1991). "Iusnaturalismo". En N. Bobbio, et al., Diccionario de política, México: Siglo XXI.

Fink, Beatrice (1989). "The Case for a Political System in Sade". En Sade: His Ethics and Rhetoric, New York: Peter Lang.

González-Torre, Ángel Pelayo (2006). La sombra de la Ilustración. Tres variaciones sobre Sade, Santander: Servicio de publicaciones de la Universidad de Cantabria.

Gourbin, Gilles (2016). "Faut-il étouffer Sade? Les avatars du «raisonneur violent» chez Rousseau et Sade (2e partie)". Recherches sur Diderot et sur l'Encyclopédie Vol. 51, pp. 41-62. Recuperado de http://journals.openedition.org/rde/5383; DOI: $10.4000 /$ rde. 5383

— (2015). "Faut-il étouffer Sade? Les avatars du « raisonneur violent » chez Rousseau et Sade". Recherches sur Diderot et sur l'Encyclopédie Vol. 50, pp. 61-81. Recuperado de http://journals.openedition.org/rde/5284; DOI : 10.4000/rde.5284

— (2014). "Diderot aurait-il étouffé Sade?”. Le Portique Vol. 34 (en línea). Recuperado de http://journals.openedition.org/leportique/2803

Hobbes, Thomas (2007). Leviatán, traducción Antonio Escohotado, Buenos Aires: Losada.

- (2000). De Cive, traducción, prólogo y notas de Carlos Mellizo, Madrid: Alianza.

- (1649). Elemens philosophiques du Citoyen, traducción de La Sorbière, Amsterdam: Imprimerie Iean Blaev.

Laborde, Alice (1974). Sade romancier, Neuchâtel: La Balconnière.

- (1972). "La notion d'isolisme et ses implications lyriques dans l'œuvre du marquis de Sade". Studies on Voltaire and the Eighteenth century Vol. 88, pp. 871-880.

Mársico, Claudia (2013). Los filósofos presocráticos. Testimonios y fragmentos I: Megáricos y cirenaicos, Buenos Aires: Losada. 
Montesquieu, Charles louis de Secondat (1998). Del espirirtu de las leyes, introducción de E. Tierno Galván, traducción de M. Blázquez y P. de Vega, Madrid: Técnos.

- (1979). De l'esprit des lois, t. I-II, introducción y notas de V. Goldschmidt, Paris: GF Flammarion.

Mothu, Alain (1995). "La bibliothèque de Sade à Lacoste". En M. Lever, Papiers de famille 2. Le marquis de Sade et les siens (1761-1815), Paris: Fayard.

Roger, Philippe (1995). "A political minimalist". En Allison, D., Roberts, M., Weiss A. (Eds.), Sade and the narrative of transgression, New York: Cambridge University Press.

Rousseau, JeAn-Jacques (2009). El origen de la desigualdad entre los hombres, Buenos Aires: Cooperativa Encuentro.

- (2008). Discours sur l'origine et les fondements de l'inégalité parmi les hommes, introducción y notas de B. Bachofen \& B. Bernardi, Paris: GF Flammarion.

Sade, Donatien Alphonse François (1990; 1995;1998). Euvres, t. I-III, introducción y notas de Michel Delon, Paris: Gallimard-Pléiade.

- (2009). Juliette o las prosperidades del vicio, traducción de Pilar Calvo, Barcelona: Tusquets.

Spector, Céline (2016). Éloges de l'injustice. La Philosophie face à la déraison, Paris: Seuil.

Thielemann, Leland (1951). “Thomas Hobbes dans l'Encyclopédie”. Revue d'Histoire littéraire de la France, no 51, pp. 333-46.

Schwarzböck, Silvia (2001). "Ni pasiones ni política: el problema de la soberanía en Sade”. ADEF: Revista de Filosofía, no 1, pp. 101-110.

Trousson, Raymond [Ed.] ([1993] 2001). Thérèse philosophe, ou Mémoires pour servir à l'histoire du Père Dirrag et de Mademoiselle Éradice. En Romans libertins du XVIIIe siècle, Paris: Éditions Robert Laffont.

Warman, Caroline (2002). Sade: From Materialism to Pornography, Oxford: Voltaire Foundation.

Recibido: 19/03/2018

Aceptado: 19/07/2018

Este trabajo se encuentra bajo una licencia de Creative Commons ReconocimientoNoComercial-SinObraDerivada 4.0 